\title{
Opportunities and Challenges for Big Data in Agricultural and
}

\section{Environmental Analysis}

\author{
Alfons Weersink (aweersin@uoguelph.ca) \\ Dept of Food, Agricultural and Resource Economics \\ University of Guelph \\ Guelph, ON Canada N1G 2W1 \\ Evan Fraser (frasere@uoguelph.ca) \\ Arrell Food Institute and Dept of Geography \\ University of Guelph \\ Guelph, ON Canada N1G 2W1 \\ Dave Pannell (david.pannell@uwa.edu.au ) \\ Centre for Environmental Economics and Policy \\ University of Western Australia \\ Perth WA 6009, Australia \\ Emily Duncan (edunca01@uoguelph.ca) \\ Dept of Geography \\ University of Guelph \\ Guelph, ON Canada N1G 2W1 \\ Sarah Rotz (rotz@uoguelph.ca) \\ Dept of Geography \\ University of Guelph \\ Guelph, ON Canada N1G 2W1
}

Keywords: digital revolution, precision agriculture, economics, policy, Big Data

\section{Acknowledgements}

Funding for this paper came from a range of sources including: The Canada First Research Excellent Fund's Food from Thought Initiative, The Canada Research Chair Program, and the Ontario Ministry of Agriculture, Food and Rural Affairs. We would also like to thank Graeme Doole and an anonymous journal reviewer for timely, encouraging and thoughtful critiques of an early draft of this paper.

Weersink, A., Fraser, E., Pannell, D., Duncan, E. and Rotz, S. (2018). Opportunities and challenges for big data in agricultural and environmental analysis, Annual Review of Resource Economics 10: 19-37. https://doi.org/10.1146/annurev-resource-100516-053654 


\begin{abstract}
Agriculture stands on the cusp of a digital revolution and the same technologies that created the Internet and are transforming medicine are now being applied in our farms and on our fields. Overall, this "digital agricultural revolution" is being driven by the low cost of collecting data on everything from soil conditions to animal health and crop development along with weather station data and data collected by drones and satellites. The promise of these technologies is more food, produced on less land, with fewer inputs and a smaller environmental footprint. At present, however, barriers to realizing this potential include a lack of ability to aggregate and interpret data in such a way that it results in useful decisionsupport tools for farmers all the way through to a need to train farmers in how to use new tools. This paper reviews the state of the literature on the promise and barriers to realizing the potential for big data to revolutionize agriculture.
\end{abstract}




\section{INTRODUCTION}

Data on farm inputs, such as fertilizer application rates, and outputs such as yields, have traditionally been collected by farmers and others involved in agricultural production. Similarly, data on the environmental impacts of production have traditionally been gathered by government agencies to monitor ecological health. While data have always been the basis for making management decisions, the amount of data collected on farm through sensors like yield monitors, portable devices, drones and smart phones has increased dramatically over the last decade. Not only are there far more data, but its form has also changed, transitioning from simple numerical values attached to variables (i.e. yield, water quality) to include more qualitative measures (i.e. type of practice, odor). Both types of variables are being gathered more precisely and at a highly localized scale.

Excitement over the potential ability of the upcoming "digital agricultural revolution" to increase productivity while reducing the sector's environmental impact has coincided with increased investment in agricultural data management by multinational corporations-firms whom are typically involved in other areas of agricultural production. For example, Monsanto purchased the hardware and software company Precision Planting in 2012 and subsequently purchased the weather data and modeling technology company Climate Corp the following year. As well, Dupont has partnered with John Deere to provide a wireless data-transfer system and then with DTN to provide market and weather information. In order to increase the machine-learning capabilities of its farm equipment, John Deere has subsequently bought Precision Planting from Monsanto and recently bought Blue River Technologies (Lev-Ram, 2017). Broadly speaking, devices for gathering data in agriculture are projected to grow from 30 million devices in 2015 to over 75 million devices by 2020 (Chi et al., 2017). Other entrepreneurs have followed this wave of investment into digital services for the agricultural sector. Despite the huge amount of interest, this much- 
heralded technological revolution has been slow to actually change agricultural practices (Brown, 2017). For instance, while venture-capital investments in agri-food have nearly doubled in each of the last two years, there has been a shift away from a focus on data (Pitchbook, 2017). The potential benefits from Big Data remain, particularly if the applications are expanded to include genomics and traceability rather than precision agriculture alone. That said, the shift in investment suggests the need to take stock, and to consider the potential role of policy in this space.

The purpose of this paper is to review the opportunities and challenges presented by Big Data for the agricultural sector, with a focus on how the natural environment is being affected by agri-food digitalization. We focus primarily on the policy issues arising from the development of Big Data and the associated analysis required to help address these policy issues. We begin by defining Big Data and its potential application for agriculture in developed countries across three domains: genomics, precision farming, and traceability. We do not extend the analysis to include developing countries, although their benefits from Big Data are also potentially large, such as through the collection of national statistics, enhanced banking services, and improved extension delivery (Deichmann et al., 2016; Kshetri, 2016).

\section{BIG DATA AND AGRICULTURE 4.0}

The emerging use of data in agriculture heralds a new "digital agricultural revolution" being driven by a number of innovations that have affected manufacturing more broadly for decades (Deichmann et al., 2016). First, advances in robotics have allowed a far greater degree of automation than has previously been possible (Faulkner and Cebul, 2014; Wolfert

et al., 2017). Secondly, the declining cost of sensor technology has allowed farmers to monitor factors such as animal movement, soil health and soil moisture in almost real-time 
conditions (Faulkner and Cebul, 2014; Joint Research Centre (JRC) of the European Commission, 2014). Thirdly, computing power to analyze these data is now sufficiently accessible and affordable to allow the creation of decision-support tools such as on-tractor dashboards and mobile applications that help farmers become more precise with their management practices such as input applications (Antle et al., 2017; Krintz et al., 2016; Rose et al., 2016). All of this is possible because of emerging Big Data analytical platforms-such as cloud computing and machine learning algorithms-that drive artificial intelligence (Ali et al., 2016; Chen et al., 2014; Krintz et al., 2016; Wolfert et al., 2017).

Together, these technologies have allowed an exponential increase in the volume, velocity, variety, and veracity of data generated in agriculture (De Mauro et al., 2016; Sonka, 2014; Wolfert et al., 2017). In turn, agricultural data are rapidly becoming a major driver not only of innovations in output and the food chain but also in environmental management (Caron et al., 2014). Often defined under the broad umbrella of "precision agriculture", Agriculture 4.0 technologies refer to production systems that deploy robotics, sensors, and big data analytics in order to enable farmers to manage their farms on much smaller, and thus more precise, spatial and temporal scales (Lesser, 2014; Wolfert et al., 2017). While precision agricultural technologies have been in use for approximately a decade, and generally take the form of yield monitors in cropping systems and robotic milking parlors for dairy, the pace of innovation in this field has picked up as the cost of sensors and robotics has fallen.

The technological innovations associated with Big Data herald a potentially profound change to farming that, for fifty years, has been dominated by Green Revolution technologies. The Green Revolution was based on the introduction of hybridized seeds, irrigation, mechanization and low-cost fertilizers and pesticides (Tilman, 1998). These technologies had the effect of increasing the scale of agriculture, in essence giving farmers 
the tools to boost yields by standardizing management practices across large areas of land (Duffy, 2009; Matson et al., 1997). The same trends occurred in the livestock industry where confined animal feeding operations, concentrated feeds, yield-boosting genetics, and mechanization have led to economies of size, resulting in significant increases in herds or flocks managed in essentially the same way (Weis, 2013).

As noted above, the tools of Agriculture 4.0 - robotics, sensors, and big data analytics platforms - will, when fully realized, allow farmers to be more precise in their application of inputs. Therefore, in many ways, Agriculture 4.0 represents a fundamentally different approach to farming than the Green Revolution. In particular, artificial intelligence, decision support systems, sensors, and robotics, allow farmers the opportunity to tailor management at much finer scales. Ultimately, these technologies may even allow farmers to manage the needs of individual animals or plants in real time. For instance, smart tractors "know" where they are in the field, plant the right seed in the right place, and give it the right amount of fertilizer (Ramundo et al., 2016; Wolfert et al., 2017; Gebbers and Adamchuk 2010). Similarly, "smart" livestock operations identify each animal as they approach a feeding station and deliver a tailor-made ration designed to meet the needs of that animal's genetics, health, and life stage (Busse et al., 2015)). In essence, the tools of Agriculture 4.0 provide the equivalent of personalized medicine but applied to crops and livestock.

It is the third component of these technological developments-the big data analytics platforms-that underpin Agriculture 4.0, and are, therefore, the most relevant for the purposes of this paper. In particular, the vast amounts of data being currently generated on farms by the robotic milkers and yield monitors currently in use are useless unless that data can be curated in ways that can be turned into useful decision-support tools for farmers (Janssen et al., 2017; Lindblom et al., 2017). As a result, big data analytic platforms will need to act as the backbone of the new agricultural revolution and will be essential to aligning 
and interpreting data, as well as creating decision support tools that support actors across the agri-food sector.

\section{OPPORTUNITIES OF BIG DATA IN AGRICULTURE AND FOR THE ENVIRONMENT}

Proponents of 'Agriculture 4.0' suggest it offers the potential for profound advances in agrifood systems in a number of key dimensions.

- First, it is expected that these technologies will speed up, and reduce the cost of, improving the genetics of our crops and livestock, not only by making breeding plants and animals more precise but also through novel technologies like gene editing. Improving the genetics of our crops and livestock will have many benefits including the opportunity to develop genotypes that are adapted to changing local conditions.

- Secondly, these technologies will likely offer some farmers the opportunity to produce more food on less land with fewer environmental impacts, commonly referred to as sustainable intensification (Garnett et al., 2013).

- Finally, these technologies offer the potential to create much greater transparency and traceability in complex global food supply chains (Opara, 2003; Bakhtiari and Hematian, 2013). Each of these opportunities are discussed in more detail below.

\subsection{Genomics}

While farmers have been breeding plants and animals since the dawn of agriculture about 10,000 years ago, recent advances in genomic technology and in particular our newfound ability to edit genes provides us with an exponentially greater degree of control over the 
genotypes that farmers utilize without raising the same ethical and environmental concerns as has been common with transgenic organisms. In particular, cutting-edge gene editing technologies allow plant and animal breeders, once they have identified a plant or animal with a specific trait, to determine what alleles are responsible for that trait. Subsequently, by turning on or off relevant genes, they use gene-editing technology to ensure that the specific trait is present or absent in future generations. This process greatly speeds up plant and animal breeding for specific traits, such as pest resistance or feed efficiency, without introducing novel genetic material into a plant or animal's genotype (Goddard, 2012; Ballenger et al., 2016). In essence, gene editing allows traditional plant breeding to proceed at a much faster pace and with far fewer regulatory, consumer, health or environmental concerns. In theory, this technology is also much cheaper to deploy than more traditional biotechnology approaches (such as transgenic or GMO), which may offer the opportunity for local biotech companies serving small markets to develop tailor-made crop and livestock phenotypes suitable for local environments.

Additionally, by reducing the amount of time it takes to create new plant and livestock variations, gene editing may also offer the ability to adapt crops and livestock more quickly to changing environmental conditions (Edwards, 2016). In the future, where we expect existing farmland to be subjected to more extreme weather conditions, as well as changes in temperatures and precipitation, the opportunity to quickly adapt crops to local conditions may become extremely important. Other environmental benefits from genetic improvements include the possibility of introducing genes encoding nitrogenase directly into cereal crops, thereby giving these plants the ability to fix their own nitrogen from the air (Beatty et al., 2011). The associated reduction in fertilizer use, and thus the potential reductions in nutrient emissions into either water bodies or the atmosphere, could also be 
achieved through understanding how genotypic expression interacts with environmental conditions to affect traits and impacts such as $\mathrm{N}$ emissions (Ng et al., 2016).

\subsection{Precision Agriculture}

The overarching objective of precision agriculture is to increase agricultural management efficiency through identifying ways of tailoring planting, fertilizing, irrigation and pesticide applications to the spatial and temporal micro-climates that exist on each farm. This represents a major departure from recent farm history. Nearly all farming systems used to be labour-intensive, and farmers managed the unique characteristics of their small operations differently according to their own assessments. Since the 1940s, however, developments in mechanization, along with other Green Revolution technologies such as hybridized seeds and relatively low-cost fertilizer and pesticides, drove many farmers to increase farm size by replacing labour with capital. One consequence of this was that the management of individual farms evolved to one in which the entire farm was treated as a single unit with relatively uniform management practices (Sonka, 2016). This has had the consequence of creating extremely homogenous agricultural landscapes and has reduced the biological, crop and social diversity of rural North America.

Precision agriculture, which allows for much smaller scale management, may theoretically change this. On one hand, precision agriculture should allow for a return to more intense agro-ecological systems that allow for an increase in heterogeneity across space and time on the farm by giving farmers the ability to manage at the level of the individual animal or within field variability. This is likely to increase both biodiversity and crop diversity. On the other hand, precision agricultural technologies tend to be very capital intensive so these technologies may lead to continued farm consolidation and socioeconomic homogeneity (Wolfert et al., 2017). Hence, there is little evidence that 
technologies such as yield monitors and variable application rate fertilizers have radically changed farm management in the past 10 years that they have become more commonly used. As noted, precision agricultural technologies may be accelerating the speed at which farms both become more consolidated and specialized. Nevertheless, a quantitative metaanalysis of the factors that led farmers to embrace best management practices (including adopting precision agricultural technologies) suggest that social factors such as are not generally significant in determining adoption (Baumgart-Getz, et al. 2012). From this, it seems that fully using these technologies may exceed the limited capacity that most farmers have for complex data-driven analysis.

Nevertheless, while the benefits of the digital agricultural revolution remain in the future, the promise of using these technologies to improve the environmental management of our food system are real. For instance, in livestock operations, many animals in any given herd typically have access to more feed than they can efficiently metabolize, and this results in nutrients being lost to the environment through manure. Similarly, it is estimated that large-scale crop systems in North America receive up to 50\% more fertilizer than the plants can absorb. These surplus nutrients from both crops and livestock operations end up either as a source of water pollution or as a greenhouse gas and contribute to global warming (Tilman et al., 2002). One consequence of uniform management over a large scale, and the subsequent excess input use, therefore, is that agriculture is the world's largest contributor to water pollution on the planet and is responsible for upwards of $30 \%$ of global greenhouse gas (GHG) emissions (IPCC, 2014). Precision agriculture should be able to address at least some of these issues. For instance, Balafoutis et al. (2017) present a review of precision agriculture technologies and conclude that GPS guidance systems combine with variable rate nutrient application can help limit the number of times a tractor drives over a field and this will reduce GHG emissions. 
But despite these obvious benefits, it must be noted that the value of the additional information provided from precision agriculture relative to its cost is another likely barrier that stand in the way of wide-spread adoption. In particular, the history of how farmers use technologies like yield monitors and variable application rate fertilizers suggest that there seems to be a relatively flat pay-off function for these technologies that in many cases means that there is no real financial incentive for farmers to invest. Hence, the existing evidence points to extremely varied uptake. In terms of livestock, precision agricultural technologies that include robotic milkers and mobility trackers to identify the estrous cycle are becoming common place in dairy operations. In terms of crop production, studies across a number of jurisdictions ranging from Europe (http://www.cema-agri.org/page/farming40-future-agriculture), the U.S. Midwest (Erickson and Widmar, 2015), Kansas (Griffin et al., 2017) and Ontario, Canada (Mitchell et al., 2017) have found widespread adoption of Global Positioning System (GPS) automated-steering systems, yield monitors, and grid soil sampling. In contrast, these studies found variable rate technologies that can apply different rates of inputs (such as seed or fertilizer) to different management zones across a field have not been adopted to the same level.

The GPS technologies are referred to as "embodied-knowledge" technologies since no additional skills are required to capture its value. Rather, such technologies rely on the knowledge that farmers already possess regarding how to operate their machinery (Griffin et al., 2017). These technologies either simplify the work (e.g. auto-steer systems) or passively collect data (e.g. yield monitors). In contrast, "information-intensive" technologies (e.g. variable rate technologies) uses data collected from the farm as input into a decision support system that generates a prescription for the variable application of inputs to reap the benefits (Griffin et al., 2017). 
The spatial detail captured by yield monitors, that are now standard equipment on most combines, has increased significantly over the last two decades. These maps indicate productivity zones across a field based on previous years' yield (hence, zones can vary across years depending on micro-conditions). Identifying high and low productivity management zones is useful and should help farmers turn parts of their field that are chronically under-productivity into setasides, while farming the highest quality zones most intensively. To reach such a potential, however, a decision model along with other soil and weather data is necessary to determine whether a high- or low-yielding area should receive more or less fertilizer than the uniform rate currently applied. By contrast, such decision support systems are not required for precision agriculture technologies such as GPS systems that increase the accuracy of input application by reducing overlap and underlap. The adoption rates of these GPS technologies suggest the benefit of easier operation plus the value of reducing input use by only applying inputs where necessary (no overlap), or from ensuring that all locations or animals are sufficiently treated (no underlap) is greater than the cost of adopting these technologies (Schimmelpfennig, 2016).

The difficulty of generating significant information value from precision technologies is illustrated through two conclusions that emerged from a series of studies that examined why farmers tend to apply more than recommended rates of fertilizer (Pannell, 2006; Rajsic and Weersink, 2008). Firstly, the response of yield to nitrogen is flat around the optimum within a given year, while the decline in the yield is small for a large range of input levels around the rate that maximizes profit. Thus, while different spatial units could receive significantly different rates of an input, the differences in profit relative to applying a uniform rate is fairly small. Secondly, the response function shifts depending upon the year. The temporal variation in yield to a given nitrogen rate is greater than the spatial variation - so adjusting rates from year to year is more important than adjusting 
rates within a field or even between fields. Rogers et al. (2016), however, suggest a means to identify fields that are most suitable for VRT management, and show that the returns to site-specific crop management are increased if the relative curvature of pay-off functions is considered.

The value of Big Data for farmers may primarily accrue through the identification of problem areas for a given site or through the development of improved analysis derived from the integration of data across many production sites (Bennett, 2015). The information from an individual producer can be integrated with data from other farmers to enhance the value of that data through the development of a decision models such as dashboards, apps and other software applications. Since the production cycles in agriculture tend to be comparatively long, there are not enough repeated observations from a single farm to generate a predictive model for that farm. However, the inclusion of variables, such as soil quality, weather conditions, and management practices, from a number of operations across a broader spatial and temporal scale than a single farm allows for a more robust analysis of the factors determining yield (Sonka, 2016). Achieving such an integration, however, requires numerous farmers using a range of different types of equipment to be able to aggregate and pool their data. Currently, such integration is lacking and this represents another likely reason why the potential environmental benefits of precision agricultural technologies have not been fully realized to date.

In the future, the core of any such decision model must be derived from the data collected across a number of producers and will be a production function relating output to inputs and very specific geographic conditions. Most agricultural and resource economists are well-versed in the importance of this technical relationship between inputs and outputs; a decision model would use the estimated production function to suggest application rates depending on the specific objectives of the producer. Economists are also aware that the 
production function is not deterministic, but inherently stochastic. Exogenous variables, such soil moisture, may have not been measured accurately at the appropriate time in the initial collection of the data or are not known when the input decision has to be made, in turn, a forecast must be made. Even if the variables can be observed or determined with certainty, the effect of these variables on production often depends on a number of unobserved variables. This uncertainty influences the accuracy of the decision model and the subsequent value of the information from precision agriculture.

The ability to derive decision rules in agriculture with high information value will be highest for sectors with (1) valuable output (single animal vs single plant), (2) a short cycle (daily vs annual), (3) small uncertainty in production, (4) high within field or betweenanimal heterogeneity, and (5) technologies to accurately and reliably measure that heterogeneity. For example, the value of precision agriculture will likely be higher for feed use in hog production where feed makes up $70 \%$ of the costs of raising a hog than for nitrogen use in field corn production, hence it would be expected that the uptake of PA technologies would be faster amongst hog farmers than corn producers. Within crop production, the net benefits of precision agriculture for nutrient decisions will likely be higher for intense greenhouse-based systems than for field crop production.

Overall, the promise of precision agriculture is more food produced on less land and with fewer inputs. As such, precision agriculture is one tool that farmers will use in order to "sustainably intensify" food systems (Garnett et al., 2013). This harkens back to debates around agriculture and the fate of wild nature from approximately ten years ago when scholars debated whether it was better for the environment to intensify agriculture, thereby "sparing" land from farming, or to adopt agricultural management practices that tried to blend ecosystem services and food production [a.k.a. the land "sharing" strategy] (Green et al., 2005; Luskin et al., 2017). While there was no specific resolution to this "sparing versus 
sharing" debate, most scholars writing about sustainable intensification suggest that the emerging agricultural technologies associated with precision agriculture will help us intensify food production while reducing inputs (Benton et al., 2011; Phalan et al., 2016).

\subsection{Traceability}

Another major benefit of the emerging agricultural technologies is the opportunity to ensure greater transparency across global food supply chains. Food system transparency is emerging as a major issue for a number of reasons (Badia-Melis et al., 2015). First, there have been mounting concerns over the past ten years around issues such as "food fraud", where inferior food is intentionally mislabeled (Aung and Chang, 2014; Van Rijswijk and Frewer, 2012). Issues around food fraud entered the public's consciousness in 2013 when it was discovered that horsemeat had been mixed into ground beef in the European Union (Walker et al., 2013). Since then, issues around food fraud have emerged with some regularity. For instance, research in Canada suggests $25 \%$ of seafood sold is mislabeled as a commercially more expensive product (Van Rijswijk and Frewer, 2012; Wong and Hanner, 2008). Similarly, increasingly discriminating middle-class consumers in Asia are demanding guarantees about the identity and providence of their food. Finally, research in North America suggests consumers are increasingly demanding to know where their food comes from and that media plays a significant role in their perceptions (McCluskey et al., 2015).

As a result, genomic-based technologies, such as DNA barcoding, are increasingly being used to verify the origins of food within global supply chains (Pizzuti and Mirabelli, 2015). Similarly, voluntary accounting systems are increasingly common as a way of offering the consumer guarantees as to the identity of their food. In an increasingly fractured and competitive global marketplace, farmers are seeing such systems as a way of guaranteeing to consumers the identity and composition of their food. Increasingly, 
industry players are looking to technologies such as IBM’s "Blockchain"

(https://www.ibm.com/blockchain/), which refers to a system of bookkeeping that

"chains" entries in a computerized ledger in such a way that they cannot be tampered with

and, therefore, can be used by a range of stakeholders to verify the authenticity of a product that has moved from producer to processor to shipper to retailer. Because blockchain ledgers are stored on a range of cloud computing servers, and there are multiple copies in multiple locations, there are no single points of failure or vulnerability for a blockchain. This characteristic has led to pioneering use of blockchain to track crypto currency transactions (e.g. bitcoin). The agri-food sector is just now considering how to use blockchain to guarantee transparency and in one of the first applications of this to food, blockchain is being pioneered by Walmart as a way of tracking pork chops (Popper and Lohr, 2017).

The digital revolution in agriculture is also allowing the concept of traceability to be expanded to include characteristics associated with the process by which the food item has been produced (Marvin et al., 2017; Lusk, 2017). Niche markets have arisen for the delivery of characteristics that are often associated with adjectives surrounding the food product, such as organic, local and range-free. Economic growth has provided consumers with the opportunity to satisfy their concerns about how their food is produced rather than just assuring a low cost (Campbell, 2009; Caracciolo et al., 2016). Currid-Halkett (2017) describes "inconspicuous consumption" as a means for the elite to signal their difference from others through activities such as buying such niche products as pasture-raised eggs and quinoa crackers. Information technology has not only fostered the spread of awareness of alternative food products (as well as potential misinformation), it has also allowed producers to verify to consumers the product contains the desired attributes. In many 
cases, the desired attribute of the food is associated with production practices that have relatively low environmental impacts, as discussed below.

\section{CHALLENGES OF BIG DATA IN AGRICULTURE AND THE ENVIROMENT}

The challenges for Big Data and achieving the potential benefits for agricultural productivity and environmental health are classified by Wolfert et al. (2017) as technical or organizational. The technical issues regarding the quality, accuracy and compatibility of the data can be solved if the costs of data acquisition continue to fall and value can be generated by innovations (Lesser, 2014). The organizational issues regarding data governance and market power from possessing the data are discussed below.

\subsection{Data Governance}

Developing Big Data analytics platforms is extremely challenging. To move data from equipment to servers, farms usually have to have access to the Internet, which is still challenging even in many rural parts of North America, let alone across the Global South (Pant and Hambly Odame, 2017). Data have to be collected in a consistent fashion and compliant with protocols that allow it to be pooled into centralized servers that must be protected from cyber security attacks while hiding the identity of individual farm managers (Chi et al., 2017). Ownership agreements between farmers, app developers and equipment manufacturers need to be established. There are, therefore, extremely challenging issues pertaining to the governance, oversight, ownership and regulation of agricultural and food data along with profound technical challenges to ensure widespread "interoperability" (e.g. that the data collected from numerous individual operators can be pooled consistently) (Banham, 2014; Janssen et al., 2017; McAfee et al., 2012; Porter et al., 2014). The difficulty 
in linking data across spatial and temporal scales is also a major challenge for using Big Data to address environmental health issues (Fleming et al., 2018).

At present, there is a somewhat chaotic and fractured "data ecosystem" as major corporations, government bodies, and universities all grapple with the challenge of establishing coherent data regulation frameworks or standardized protocols to allow the promise of the technologies to be realized. The interest in agricultural technology by large companies, such as Monsanto and John Deere, presents both opportunities and challenges in this respect. Large vertically integrated multinational enterprises could create muchneeded integrated data systems to support agriculture and food production. As demonstrated by Walmart's use of blockchain in the pork sector (see above), such companies have the resources and connectivity across the food value chain to establish the large-scale data analytics framework that is needed. However, there are questions of equity, and in particular whether a corporate-controlled data-analytics platform for agriculture is the most efficient way of promoting the public good, protecting the consumer, and helping the world's small-scale farmers who have already been marginalized and stand to be further disenfranchised by this new wave of data-intensive technologies.

It is the role of policy, therefore, to proactively identify and address such equity issues and potential market failures (Shin and Choi, 2015). We note the "GODAN" (Global Open Data for Agriculture and Nutrition) (www.godan.info) initiative is attempting to create an open data platform for agriculture and nutrition based on the partnership of both public and private players. In Canada, work is underway between the University of Guelph and a range of government agencies along with IBM to provide a Canadian-made solution to the challenge of data integration, and the need for a big data analytics platform, for the food and agriculture sector. Toward Precision Farming 2.0 is a collaborative effort in the Netherlands involving several universities, government and industry to integrate data 
collection, management, analysis and decision making at the farm level. Similarly, Woodward (2016a) proposes a single comprehensive data warehouse that would coordinate the aggregation, sourcing and distribution of the increasing amount of economic and environmental data on the agri-food sector.

Another barrier that inhibits precision agriculture relates to rural connectivity. Across many rural areas of North America and Europe, there is a lack of broadband (Pant and Hambly Odame, 2016). This is particularly pronounced in Canada where the government has identified rural connectivity is a major priority (CRTC, 2016). Additionally, demographic trends may also be a barrier (Pierpaoli et al., 2013). In particular, older farmers are less likely than younger farmers to utilize the Internet and, therefore, adopt precision agriculture technologies involving accessing the internet and analyzing data (Tey and Brindal, 2012). Given that the average age of farmers across North America and Europe is around 55 years of age and increasing, it is to be expected that the aging farm population present a barrier (Statistics Canada, 2017).

\subsection{Asymmetric Market Information}

Monsanto's acquisition of Climate Corp. and John Deere's purchase of Blue River Technology are recent examples of mergers within the realm of Big Data but these deals are part of a bigger trend within the agricultural sector (Clapp and Fuchs, 2009; Howard, 2016). In recent years, the chemical company Bayer itself purchased Monsanto, DuPont and Dow Chemical merged, and Syngenta was purchased by ChemChina. Altogether, these mergers and acquisitions have led to significant industry concentration with the percentage of global corn and cotton seeds accountable by the largest for companies growing from 60 to $85 \%$ for corn and 50 to $75 \%$ for soybeans (Macdonald, 2016). 
Increased concentration at both producer and retail ends of the agri-food supply chain has led to concern about corporate control over data flows (Bronson and Knezevic, 2016). For example, Monsanto's Integrated Field Systems (IFS) collects information for farmers on variables such as soil health and pest pressures but this data could also be used by the company to promote their own pesticides and to identify new R\&D needs. Similarly, at the other end of the chain, food processors and retailers monitor social media to predict consumer trends and attributes valued by the market place. The information collected on production costs and market demand has implications for market power between players in the food system. The extent of the asymmetry in market information and its potential impact on the distributional impacts of the digital revolution is the impetus for the negotiations regarding data ownership alluded to in the previous section.

\section{POLICY ISSUES}

\subsection{Agricultural Policy}

Agricultural policy was initially designed to help improve the financial well-being of the farm family and subsequently the rural economy (Gardner, 1992; Schmitz, 2010). Given the historic homogeneity of the farm sector, in which a single farm tended to be operated by a single farmer and supported a single farm family, policies such as extension efforts or commodity price support programs were effective at enhancing farm family income (Poon and Weersink, 2014). The distribution of farm size tended to be normal; for example, the average and median herd size for dairy farms in Ontario was around 40 cows in the early 1990s. Technical innovations including the digital revolution have led to a significant reduction in the number of farms with the decline largely occurring in mid-size units resulting in farm size distribution (Weersink, 2017). 
In addition to changes in the number of farms and their size (horizontal boundaries), the degree of specialization (vertical boundaries) and the resulting structure of the sector has also been altered by the reductions in the cost of monitoring production. Farms have tended to perform a number of activities internally; for example, many livestock farms have grown and harvested their own feed. The gains from specialization, such as harvesting feed or raising livestock, have been limited due to the short and infrequent production stages in farming and from the greater efficiencies of farmers doing the work themselves due the cost of monitoring hired labour and the stochastic nature of farm production (Allen and Lueck, 2004). However, the emerging Big Data revolution is in the process of reducing measurement cost of operations and, given the associate fall in transaction costs, farms have become more specialized. These larger, more specialized farms may or may not be selling into niche markets that, as discussed earlier, have arisen with developments in information and communication technologies. The net result is a continuation of the trend from many, homogeneous farms to fewer, that are more heterogeneous (when compared with other farms) but more specialized in terms of the specific actions and practices employed on a single operation.

The growing differentiation of the farm sector fostered by the digital revolution complicates the assessment and design of farm policy. In North America, the rapidly declining number of mid-sized farms, combined with a growing share of farms producing for niche markets as well as the rise of very large farms producing for commodity markets means that it is difficult to determine who is the "average farmer" or what is an "average farm" (Weersink, 2017). Whereas the average numbers generated through statistical databases were representative of the typical producer a generation ago, this is less and less true as middle-sized operations decline (Lyson et al., 2008). Thus, assessing the economic 
conditions for farmers, and the consequent need for agricultural policy, requires looking beyond the average numbers.

While one-size-fits-all programs were perhaps more appropriate when farms were similar, the growing heterogneity requires targeting programs to particular producers in order to deliver policies that effectively support farms of all scales. The policy objective of improving the livelihood of farmers has shifted toward improving the competitiveness of the sector, but for which of its components: the farm or farmer?, the small or large farm?, owner or operator? the niche or commodity producer? Traditional North American support programs that address commodity production and price risk may need to be complemented by other programs that address market and supply chain risks associated with farming for niche markets. The growth in niche markets and specialization has meant that exchange is now done through contracts between growers and processors to ensure the timing and quality of delivery (Adjemian et al., 2016). In turn, risk has subsequently shifted from price risk to contract risk.

The trend toward greater farm-sector heterogeneity is likely to continue and, in turn, so will the internal and external support for any policies targeted toward the farm sector. For example, farmer support in Western Canada for a single-desk selling agency called the Canadian Wheat Board, declined as more farmers felt they could do better outside of the system. Regardless of the objective and subsequent target of the policy, any evaluation of that policy will have to extend the traditional welfare analysis approach to examine its distributional effects given the growing diversity of the farm sector along with the increased concentration through the agri-food sector and the growing reliance on vertical coordination to supply products with the desired attributes (Sexton, 2012).

Crop insurance is another policy that helps reduce the risk of crop failure for all participating farmers regardless of size. In North America, crop insurance programs are 
financially supported by government through subsidized premiums yet many farmers do not insure despite the inherent uncertainty in crop production (Ker et al., 2017). Big Data offers the potential to increase the efficiency of the program by reducing adverse selection and moral hazard issues plaguing current designs. Improved understanding of the reasons for yield differences and better measurement of the actual yields by site will allow premiums to be appropriately set for individual producers thereby either increasing the overall demand for crop insurance where governments have not been involved or reducing the financial burden of governments where premiums have been subsidized (Coble et al., 2016). Enhanced measurement could also potentially reduce moral hazard behavior such as not fully harvesting a crop yielding below the coverage level, thereby further improving the financial viability of the risk management program.

In this way, Big Data and Big Data analytics platforms should also aid the expansion of crop and production insurance options available to farmers. An efficient weather insurance program requires measurable data on a climatic variable that directly influences output. However, spatial differences in the variable, such as rainfall or frost, result in significant basis risk using random weather station data. The increased ability to measure weather data at a small local scale at relatively low cost reduces basis risk and thus increases the efficiency of weather insurance (Castillo et al., 2016). Similarly, the feasibility of livestock production insurance increases with the ability to measure factors affecting disease its actual prevalence (Hoag et al., 2006).

With advances in communication and information technologies, government's role in enhancing human capital will also be increased. Advances in automation and artificial intelligence will require a demanding new skill set. As a result, education programs will be needed to prepare workers to fill this demand (Rainie and Anderson, 2017). Disruption in the labour market and the associated demand for skills-training is occurring in all sectors, 
but is particularly acute in agri-food. There is currently a labour shortage within the sector for unskilled and skilled workers across developed countries. For instance, there are over 50,000 unfilled jobs in Canadian agriculture (Conference Board of Canada, 2016).

\subsection{Agri-Environmental Policy}

The design of environmental policy to deal with residuals from the agricultural sector such as greenhouse gas emissions or nitrates - has been complicated by the nature of the production process generating those negative environmental impacts. Like many of the environmental problems associated with farming, there are many, small potential contributors to most environmental problems from agriculture, making it costly to measure specific problems such as greenhouse gas emissions from each individual farm.

Confounding these issues is the fact that the environmental impact of everything from GHGs to water pollution and antibiotic use depends on site-specific characteristics, such as soil type, management practice, and distance to nearby water bodies. Hence, the specific relationship between a farm, the farm's management practices, and the environmental impact of those practices is also stochastic and influenced by variables such as climate that are outside the control of the farmer. Even if there was a direct relationship between actions and emissions, many farming practices-such as the timing or rate of nutrient application-are costly for an outside policy agency to observe and hence regulate. The net result of these complications is that a range of policy options have been implemented with varying degrees of success.

For instance, in North America, the most common means of encouraging farmers to change on-farm practices has been through voluntary cost-share programs for a suite of beneficial management practices (BMPs) deemed to reduce the negative impacts of agricultural production (see Baumgart-Geltz et al. 2012 for a review of the drivers of BMP 
adoption). These design-based programs are common because of both their political feasibility and their focus on observable practices, sidestepping the often-high uncertainty around the correlation between the BMP and the environmental objective. Here again, we see the potential for technological developments associated with Big Data to create new opportunities for policy but these have yet to be fully realized. For instance, using sensors to monitor GHG emissions or water pollution on a sample of farms should make it possible to create predictive algorithms that are able to handle the stochasticity of local environmental micro-niches. Such tools will become used to allow policy makers to stop subsidizing BMPs to a more targeted, whole-farm approach, that focuses on directly reducing specific impacts such as GHG emissions.

In addition to identifying who should be targeted through the agri-environmental policy while also facilitating a shift from design-based management (e.g. management governed by the adoption of BMPs) to performance-based management (e.g. management driven by emission targets etc.), the digital revolution may also alter the choice of mechanism. That said, governments must decide on who should bear the cost of any program. Governments have tended to provide payments to farmers (hence adoption of a "beneficiary pays" principle) to change their existing practices, and they generally only use polluter-pays mechanisms (such as penalties or taxes) when attempting to prevent farmers from using environmentally harmful practices (Weersink and Pannell, 2017). Subsidizing the adoption of BMPs reflects the political support the farm sector has garnered over time. However, the increasing use of robotics in farming systems has shifted the public's view of commodity agriculture from a family-operated, traditional farm to an anonymouslyoperated industrial business. This shift in community perception may also shift the political feasibility of beneficiary-pays programs for agricultural producers and cause a shift towards policies based on the polluter-pays principle. 
Advances in traceability further enhance the feasible choice of agri-environmental policy options. Labeling allows firms or governments to both signal and create a demand for environmental performance. A market is thereby created that allows those desiring such an improvement to pay for it. The clearest current example is the marketing of organic products. Producer organizations and/or governments across many countries have established criteria for products to be sold as organic at a price premium. Farmers can then voluntarily decide whether to produce according to those standards, and thus sell their products for a premium as organic. In order for the organic produce market to develop, information and verification systems were required to ensure compliance to the organic standard. Part of the externality associated with excess pesticide use is internalized, allowing consumers who desire a reduction in pesticide use to pay farmers to do so through their purchase of organic products.

Methods designed to enhance food system traceability also allow the certification of goods in terms of either their direct environmental performance (i.e. carbon footprint) or the practices used to produce them (i.e. organic, range-free). Messer et al. (2017) suggest that governments should encourage the labelling of food processes but only mandate labelling if the process results in a food that could harm human health. It is important to note, however, that the ability to use labeling to enhance the ecological benefits of the agrifood sector will be greater for those further along the food supply chain (e.g. producers selling fruit at a farmers' market) than for farmers selling a bulk commodity farm removed from final consumption. Consumer demand may also be greater for attributes that are consumptive (i.e. organic vegetables) as opposed to non-consumptive (i.e. improved wildlife habitat). For any environmental performance attribute, Big Data should reduce the cost of providing enhanced traceability once the tracking systems are in place thereby ensuring that food claiming certain attributes is actually delivered by the farmer to the consumer 
thereby lowering the transaction costs of certification. Thus, the likelihood is that Big Data will allow a growth of farms who use self-regulation to meet the consumer demands for improved environmental performance increases.

Big Data can further extend the list of viable environmental policy options to include litigation, which has typically been limited to acute polluting events involving significant damages and a small number of parties. Moreover, in such cases, the linkages between cause and effect are often well-understood (Weersink et al., 1998). A potential example of Big Data's role in litigation is the case of dicamba. Specifically, Big Data may aid in determining who and what is responsible for damages caused to soybeans from the drift of dicamba in 2017; official injury investigations are underway on approximately 2.5 million acres in the U.S. Midwest (Bradley, 2017). Using data on the rate and timing of dicamba application from farmers and agricultural retailers, combined with weather data, scouting reports and in-season plant tissue maps of soybean crops, fields can be linked to postharvest yield maps to help determine responsibility for the damage (Janzen, 2017).

Many farm groups are concerned about environmental groups or government regulatory agencies using data collected on farm operations against farms who fail to comply with regulations, particularly with regards to nutrient management (Coble et al. 2016). However, the digitalization of data may also aid farms in demonstrating more clearly and precisely how their management plan satisfies external sustainability certifications thereby reducing litigation risk (Coble et al., 2016). For instance, recent studies indicate that nutrient loadings are likely caused by a few individuals rather than all producers as a group. Accordingly, documentation using data may aid more farmers and groups in verifying environmental compliance generally while exposing the small number of farmers who are polluting the environment hence creating a "naming and shaming" 
approach to environmental management where peer pressure is an important tool in promoting best practices (Leslie et al., 2016).

While the digital revolution reduces some of the complexities associated with designing environmental policy for the agri-food sector, the use of digital technologies has also fostered the growing separation between ownership and management at the farm-level as farmland owners are able to monitor the activities and output of farmer tenants. When combined with the growing attractiveness of farmland as an investment by non-farmers, there has been a continual increase in the amount of farmland that is rented-approximately $40 \%$ of farmland is rented in the United States and Canada, and much of it is on a cash rent basis (Bryan et al., 2015; Bigelow et al., 2016). Under this tenure relationship, tenants make the management decisions regarding practices for which agri-environmental policies are typically applied, but the farmland owners are the ones who may receive the payments from policy. The potential disconnect between the incentives of the program and the tenant/owner can lead to limited uptake of the policy and thus limited agri-environmental accountability (Rotz et al., 2017). For example, Palm-Forster et al. (2016) found the participation rate in a conservation auction to reduce phosphates into Lake Erie to be particularly low on rented farmland.

\section{SUMMARY}

As documented by Cukier and Mayer-Schoenberger (2013), the digital revolution has already transformed how we live, work, and think, and this is beginning to include the agrifood sector where there is a huge amount of optimism both amongst the industry as well as policy makers and environmental activists that in the future, food will be produced with a smaller environmental footprint. Bioinformatics advances are speeding up the processes by which we breed plants and animals, and are doing so at significantly lower cost. Precision 
agriculture technologies are allowing farmers to better apply inputs by giving them the tools to manage the spatial and temporal variation existing on their farm. The developments in information and communication technology are creating systems that allow for exponentially greater transparency and traceability throughout the food chain, which should not only improve environmental and human health but also allow the indstury to develop markets around those performance attributes that increasingly discriminating consumers are demanding.

However, the opportunities created by digital tools to boost both productivity and environmental improvement are limited by a number of issues including data governance, a lack of skills in how to handle and interpret data at the farm level, and an unclear return on investment for farmers who may be considering investing in new technologies. More specifically, at present our ability to generate data exceeds our ability to manage, analyze and use that data. This is made clear by the relative rate of adoption for GPS technologies, which require no additional skills, versus the adoption of variable rate application technologies, which require new skills and decision-making models. In effect, the value added from precision agriculture technologies has not, in all cases, exceed the costs. Since the agricultural production process is biological and subject to uncertainty, a wide range of different types of information is necessary to understand the underlying science and develop a decision model. These huge amounts of data need to be gathered consistently and accurately across a range of scales and then they must be analyzed and interpreted using tools such as deep learning and artificial intelligence. Finally, the interpreted data must be presented back to producers in the form of decision support tools. The difficulty of constructing, maintaining, analyzing, and sharing such data all limit the opportunity to derive effective decision rules with high information value to producers. Thus, these barriers limit the potential of Big Data across the entire sector. 
Relatedly, as data is increasingly seen as a major input to innovation and production, major questions are currently being asked about who owns data and who ultimately will benefit from the potential of big data analysis. The pace of industrial mergers in the past few years signals that major industry players are positioning themselves to take advantage of these opportunities and this leads many to wonder if a small number of techsavvy companies reap all of the rewards? Or will the benefits of this new revolution be widespread and socially inclusive? More critical voices in this debate point to lessons from the Green Revolution that provided a huge bonus for farmers who were able to take advantage of new capital intensive technology but likely marginalized millions of small farmers. Will the same thing happen with the Digital Agricultural Revolution? More specifically, since many of the technologies being discussed in this paper require little in the way of human labor, will their adoption spell a decline in our rural communities? While these issues are relevant to North America, they take on even greater significant in the Global South where many economies are still structurally dependent on agricultural labour. If the urban economy is not sufficiently developed to provide meaningful jobs to people, will a decline in rural labor simply spell an increase in urban slums? It will partially fall to policymakers to determine the extent to which we steer a course towards a greater democratization of technology and promote widespread public benefits.

There is also a question of training. A recent report by the Canadian government's "Advisory Council for Economic Growth" identified that investing in agriculture, and agricultural technologies, is a solid strategy to boost middle-class incomes and create jobs (http://www.budget.gc.ca/aceg-ccce/pdf/key-sectors-secteurs-cles-eng.pdf). But it is important to note that these new jobs do not necessarily look like traditional farm jobs. While animal husbandry and crop science will continue to be important, as is understanding how to maintain healthy soil, the upcoming jobs in the new digital agricultural economy are 
more related to: software engineering, database management, and robotics, as well as having workers with appropriate legal and policy expertise to develop and adjudicate new data sharing arrangements. Consequently, colleges and universities need to quickly revise training curriculum to ensure that the next generation of agri-entrepeneurs has the skills they need to take advantage of the opportunities afforded by technology.

To close, the digital revolution has accelerated the changes in farm structure, with consequences for agricultural policy. The growing heterogeneity in the farm sector means traditional support programs in North America that address production and price risk may need to be complemented by other programs that address market and supply chain risks associated with farming for niche markets. As it stands, the external benefits from the digital revolution may be greater than the on-farm benefits, and thus there is a role for public policy, depending on the extent of those benefits. The range of agri-environmental policy options has increased with the reduction in cost of monitoring and the ability to ensure the use of environmentally beneficial practices are employed.

\section{REFERENCES}

Adjemian, M.K., Brorsen, B.W., Hahn, W., Saitone, T.L. and Sexton, R.J., 2016. Thinning Markets in US Agriculture. Economic information bulletin-148, U.S. Department of Agriculture, Economic Research Service, March.

Ali, A., Qadir, J., ur Rasool, R., Sathiaseelan, A., Zwitter, A. and Crowcroft, J., 2016. Big data for development: applications and techniques. Big Data Analytics, 1(1), p.2.

Allen, D.W. and Lueck, D., 2004. The nature of the farm: contracts, risk, and organization in agriculture. MIT Press.

Antle, J.M., Jones, J.W. and Rosenzweig, C., 2017. Next generation agricultural system models and knowledge products: Synthesis and strategy. Agricultural Systems, 155(July), pp.179185. 
Bakhtiari, A.A. and Hematian, A., 2013. Precision Farming Technology, Opportunities and Difficulty. International Journal for Science and Emerging Technologies with Latest

Trends, 5(1), pp.1-14.

Balafoutis, A., Beck, B., Fountas, S., Vangeyte, J., Wal, T.V.D., Soto, I., Gómez-Barbero, M., Barnes, A. and Eory, V., 2017. Precision Agriculture Technologies Positively Contributing to GHG Emissions Mitigation, Farm Productivity and Economics. Sustainability, 9(8), p.13391367.

Ballenger, N., Bastian, C., Cammack, K., Feuz, B., Griffith, G. and Schaffer, J., 2016. 30 and Daisy: Where's the economics in beef cattle DNA testing?. Choices, 31(2).pp.

Banham, R., 2014. Who Owns Farmers' Big Data? Forbes. Available from: http://www.forbes.com/sites/emc/2014/07/08/who-owns-farmers-bigdata/\#211977e53ce7 (accessed 23 October 2017).

Baumgart-Getz, A., Stalker L., Floress, K., 2012. Why farmers adopt best management practice in the United States: A meta-analysis of the adoption literature. Journal of Environmental Management. 96(1), pp. 17-25

Beatty, P.H. and Good, A.G. 2011. Future prospects for cereals that fix nitrogen. Science, 333(6041, July), pp. 416-417.

Benton, T.G., Dougill, A.J., Fraser, E.D.G. and Howlett, D.J.B., 2011. The scale for managing production vs the scale required for ecosystem service production. World Agriculture, 2(1), p.11.

Bennett, J.M., 2015. Agricultural Big Data: utilisation to discover the unknown and instigate practice change. Farm Policy Journal, 12(1), pp.43-50.

Besanko, D., Dranove, D., Shanley, M. and Schaefer, S., 2009. Economics of strategy. John Wiley \& Sons.

Bigelow, D., Borchers, A., and Hubbs, T., 2016. U.S. farmland ownership, yenure, and transfer, EIB-161, U.S. Department of Agriculture, Economic Research Service, August.

Bradley, K. 2017. Ag Industry, Do we have a problem yet? Integrated Pest Management, University of Missouri, https://ipm.missouri.edu/IPCM/2017/7/Ag Industry Do we have a problem yet/

Bronson, K. and Knezevic, I., 2016. Big Data in food and agriculture. Big Data \& Society, 3(1), p.2053951716648174.

Brown, E. 2017. Why big data hasn't yet made a dent on farms. Wall Street Journal. https://www.wsj.com/articles/why-big-data-hasnt-yet-made-a-dent-on-farms$\underline{1494813720}$

Bryan, J., Deaton, B.J. and Weersink, A., 2015. Do landlord-tenant relationships influence rental contracts for farmland or the cash rental rate?. Land Economics, 91(4), pp.650-663. 
Busse, M., Schwerdtner, W., Siebert, R., Doernberg, A., Kuntosch, A., König, B. and Bokelmann, W., 2015. Analysis of animal monitoring technologies in Germany from an innovation system perspective. Agricultural Systems, 138(Sept), pp.55-65.

Canadian Radio-television and Telecommunications Commission (CRTC). 2017. https://www.canada.ca/en/radio-television-telecommunications/news/2016/12/crtcestablishes-fund-attain-new-high-speed-internet-targets.html

Carolan, M., 2017. Publicising Food: Big Data, Precision Agriculture, and Co-Experimental Techniques of Addition. Sociologia Ruralis, 57(2), pp.135-154.

Caron P, Bienabe E, and Hainzelin E (2014) Making transition towards ecological intensification of agriculture a reality: The gaps in and the role of scientific knowledge. Current Opinion in Environmental Sustainability 8: 44

Castillo, M.J., Boucher, S. and Carter, M., 2016. Index Insurance: Using Public Data to Benefit Small-Scale Agriculture. International Food and Agribusiness Management Review, 19(A).

Chen, M., Mao, S. and Liu, Y., 2014. Big data: A survey. Mobile Networks and Applications, 19(2), pp.171-209.

Chi, H., Welch, S., Vasserman, E. and Kalaimannan, E., 2017. A Framework of Cybersecurity Approaches in Precision Agriculture. In ICMLG2017 5th International Conference on Management Leadership and Governance (p. 90). Academic Conferences and Publishing Limited.

Coble, K, Griffin, T., Ahearn, A., Ferrell, S., McFadden, J., Sonka, S. and Fulton, J., 2016. Advancing U.S. agricultural competitiveness with Big Data and agricultural economic market information, analysis, and research. Report from the Council on Food, Agricultural \& Resource Economics (C-FARE), October.

Cukier, K. and Mayer-Schoenberger, V., 2013. The rise of Big Data: How it's changing the way we think about the world. Foreign Affairs., 92(2), p.28-40.

Currid-Halkett, E. 2017. The Sum of Small Things: Culture and Consumption in the 21st Century. Princeton University Press.

Deichmann, U., Goyal, A. and Mishra, D., 2016. Will digital technologies transform agriculture in developing countries? Agricultural Economics, 47, pp.21-33

De Mauro, A., Greco, M. and Grimaldi, M., 2016. A formal definition of Big Data based on its essential features. Library Review, 65(3), pp.122-135.

Duan, L. and Xiong, Y., 2015. Big data analytics and business analytics. Journal of Management Analytics, 2(1), pp.1-21.

Duffy M (2009) Economies of Size in Production Agriculture. Journal of Hunger \& Environmental Nutrition 4(3-4): 375-392. 
Edwards, D., 2016. The impact of genomics technology on adapting plants to climate change. In Plant Genomics and Climate Change (pp. 173-178). Springer New York.

Erickson, B. and Widmar, D.A., 2015. Precision agricultural services dealership survey results. West Lafayette, Indiana: Purdue University, August.

http://agribusiness.purdue.edu/files/resources/2015-crop-life-purdue-precision-dealersurvey.pdf

Evert, F.K., Fountas, S., Jakovetic, D., Crnojevic, V., Travlos, I. and Kempenaar, C., 2017. Big Data for weed control and crop protection. Weed Research, 57(4), pp.218-233.

Faulkner, A., Cebul, K., 2014. Agriculture Gets Smart: The Rise of Data and Robotics. Cleantech Agriculture Report. Cleantech Group.

Fleming, L., Kessel, A., Murray, V., Depledge, M., Leonelli, S., Tempini, N., Gordon-Brown, H., Nichols, G., Sarran, C., Vineis, P., Leonardi, G., Golding, B., \&amp; Haines, A. 2017. Big Data in environment and human health. Oxford Research Encyclopedia of Environmental Science. July http://environmentalscience.oxfordre.com/view/10.1093/acrefore/9780199389414.001. 0001/acrefore-9780199389414-e-541.

Gardner, B.L., 1992. Changing economic perspectives on the farm problem. Journal of economic literature, 30(1), pp.62-101.

Garnett, T., Appleby, M.C., Balmford, A., Bateman, I.J., Benton, T.G., Bloomer, P., Burlingame, B., Dawkins, M., Dolan, L., Fraser, D. and Herrero, M., 2013. Sustainable intensification in agriculture: premises and policies. Science, 341(6141), pp.33-34.

Gebbers, R. and Adamchuk, V.I., 2010. Precision agriculture and food security. Science, 327(5967), pp.828-31.

Goddard, M.E., 2012. Uses of genomics in livestock agriculture. Animal Production Science, 52(3), pp73-77.

Green, R.E., Cornell, S.J., Scharlemann, J.P. and Balmford, A., 2005. Farming and the fate of wild nature. science, 307(5709), pp.550-555.

Griffin, T.W., Miller, N.J., Bergtold, J., Shanoyan, A., Sharda, A. and Ciampitti, I.A., 2017. Farm's Sequence of Adoption of Information-intensive Precision Agricultural Technology. Applied Engineering in Agriculture, 33(4), p.521-527.

Hoag, D.L., Thilmany, D.D. and Green, J.W., 2006. The economics of livestock disease insurance: concepts, issues and international case studies. CABI.

Janssen, S.J.C. et al., 2017. Towards a new generation of agricultural system data , models and knowledge products : Information and communication technology. Agricultural Systems, 155, pp.200-212.

Janzen, T. 2017. Dicamba will show us the promise - and limitiations-of big data in 2017. Janzen Ag Law Blog. http://www.aglaw.us/janzenaglaw/2017/8/3/dicamba-big-data 
Ker, A.P., Barnett, B., Jacques, D., and Tolhurst, T., 2017. Canadian business risk management: Private firms, crown corporations, and public institutions. Canadian Journal of Agricultural Economics, forthcoming.

Kersting, K., Bauckhage, C., Wahabzada, M., Mahlein, A.K., Steiner, U., Oerke, E.C., Römer, C. and Plümer, L., 2016. Feeding the World with Big Data: Uncovering Spectral Characteristics and Dynamics of Stressed Plants. In Computational Sustainability (pp. 99-120). Springer International Publishing.

Krintz, C., Wolski, R., Golubovic, N., Lampel, B., Kulkarni, V., Roberts, B. and Liu, B., 2016, August. SmartFarm: Improving agriculture sustainability using modern information technology. In KDD Workshop on Data Science for Food, Energy, and Water.

Kshetri, N., 2016. Big Data's Big Potential in Developing Economies: Impact on Agriculture, Health and Environmental Security. CABI.

Leslie, J.E., Weersink, A., Yang, W. and Fox, G., 2017. Actual versus environmentally recommended fertilizer application rates: Implications for water quality and policy. Agriculture, Ecosystems \& Environment, 240(1), pp.109-120.

Lesser, A., 2014. Big Data and Big Agriculture. Gigaom Research, pp.11.

Lev-Ram, M., 2017. John Deere is paying \$305 million for this Silicon Valley company. [online]. Available at: http://fortune.com/2017/09/06/john-deere-blue-river-acquisition/ [Accessed 23 Oct. 2017].

Lindblom, J., Lundstro, C. and Jonsson, A., 2017. Promoting sustainable intensification in precision agriculture: review of decision support systems development and strategies. Precision Agriculture, pp.309-331.

Lusk, J.L., 2017. Consumer research with big data: Applications from the food demand survey (FooDS). American Journal of Agricultural Economics, 99(2), pp.303-320.

Marden, E., Godfrey, R.N. and Manion, R. eds., 2016. The Intellectual Property-Regulatory Complex: Overcoming Barriers to Innovation in Agricultural Genomics. UBC Press.

Marvin, H.J., Janssen, E.M., Bouzembrak, Y., Hendriksen, P.J. and Staats, M., 2017. Big data in food safety: An overview. Critical reviews in food science and nutrition, 57(11), pp.22862295.

Matson, P.A., Parton, W.J., Power, A.G. and Swift, M.J., 1997. Agricultural intensification and ecosystem properties. Science, 277(5325), pp.504-509.

McCluskey, J.J., Kalaitzandonakes, N. and Swinnen, J., 2015. Media coverage, public perceptions, and consumer behavior: insights from new food technologies. Annual Review of Resource Economics, 7, pp.19.1-11.

Messer, K.D., Costanigro, M. and Kaiser, H.M., 2017. Labeling Food Processes: The Good, the Bad and the Ugly. Applied Economic Perspectives and Policy, 39(3), pp.407-427. 
Misuraca, G., Mureddu, F. and Osimo, D., 2014. Policy-making 2.0: Unleashing the power of big data for public governance. In Open Government (pp. 171-188). Springer New York.

Mitchell, S., Weersink, A. and Erickson, B., 2018. Adoption of precision agriculture technologies in Ontario crop production. Canadian Journal of Plant Science.

Ng, J.M.S., Han, M., Beatty, P.H. and Good, A., 2016. “Genes, Meet Gases”: The Role of Plant Nutrition and Genomics in Addressing Greenhouse Gas Emissions. In Plant Genomics and Climate Change (pp. 149-172). Springer New York.

Opara, L.U., 2003. Traceability in agriculture and food supply chain: a review of basic concepts, technological implications, and future prospects. Journal of Food Agriculture and Environment, 1, pp.101-106.

Palm-Forster, L.H., Swinton, S.M., Redder, T.M., DePinto, J.V. and Boles, C.M., 2016. Using conservation auctions informed by environmental performance models to reduce agricultural nutrient flows into Lake Erie. Journal of Great Lakes Research, 42(6), pp.13571371.

Pannell, D.J., 2006. Flat earth economics: the far-reaching consequences of flat payoff functions in economic decision making. Review of Agricultural Economics, 28(4), pp.553566.

Pant, L.P. and Odame, H.H., 2017. Broadband for a sustainable digital future of rural communities: A reflexive interactive assessment. Journal of Rural Studies, 54, pp.435-450.

Phalan, B., Green, R.E., Dicks, L.V., Dotta, G., Feniuk, C., Lamb, A., Strassburg, B.B., Williams, D.R., Zu Ermgassen, E.K. and Balmford, A., 2016. How can higher-yield farming help to spare nature?. Science, 351(6272), pp.450-451.

Pierpaoli, E., Carli, G., Pignatti, E. and Canavari, M., 2013. Drivers of precision agriculture technologies adoption: A literature review. Procedia Technology, 8, pp.61-69.

Popper, N. and Lohr, S., 2017. Blockchain: A Better Way to Track Pork Chops, Bonds, Bad Peanut Butter. New York Times, 4.

Poon, K. and Weersink, A., 2014. Growing forward with agricultural policy: Strengths and weaknesses of Canada's agricultural data sets. Canadian Journal of Agricultural Economics, 62(2): 191-218.

Rainie, L., and Anderson, J., 2017. The future of jobs and jobs training. Pew Research Center, May. Available at: http://www.pewinternet.org/2017/05/03/the-future-of-jobs-and-jobstraining/

Rajsic, P. and Weersink, A., 2008. Do farmers waste fertilizer? A comparison of ex post optimal nitrogen rates and ex ante recommendations by model, site and year. Agricultural Systems, 97(1), pp.56-67. 
Ramundo L, Taisch M and Terzi S (2016) State of the art of technology in the food sector value chain towards the IoT. 2016 IEEE 2nd International Forum on Research and Technologies for Society and Industry Leveraging a better tomorrow (RTSI): 1-6.

Rogers, A., Ancev, T. and Whelan, B., 2016. Flat earth economics and site-specific crop management: how flat is flat?. Precision agriculture, 17(1), pp.108-120.

Rose, D.C., Sutherland, W.J., Parker, C., Lobley, M., Winter, M., Morris, C., Twining, S., Foulkes, C., Amano, T. and Dicks, L.V., 2016. Decision support tools for agriculture: Towards effective design and delivery. Agricultural Systems, 149, pp.165-174.

Schimmelpfennig, D., 2016. Farm profits and adoption of precision agriculture, ERR- 217, United States Department of Agriculture, Economic Research Service, October.

Schmitz, A., 2010. Agricultural policy, agribusiness, and rent-seeking behavior. University of Toronto Press.

Sexton, R.J., 2012. Market power, misconceptions, and modern agricultural markets. American Journal of Agricultural Economics, 95(2), pp.209-219.

Shin, D.H. and Choi, M.J., 2015. Ecological views of big data: Perspectives and issues. Telematics and Informatics, 32(2), pp.311-320.

Sonka, S., 2016. Big data: fueling the next evolution of agricultural innovation. Journal of Innovation Management, 4(1), pp.114-136.

Sonka, S., 2014. Big data and the ag sector: More than lots of numbers. International Food and Agribusiness Management Review, 17(1), pp.1-20.

Tey, Y.S. and Brindal, M., 2012. Factors influencing the adoption of precision agricultural technologies: a review for policy implications. Precision Agriculture, 13(6), pp.713-730.

Tilman, D., 1998. The greening of the green revolution. Nature, 396(6708), pp.211-212.

Tilman, D., Cassman, K.G., Matson, P.A., Naylor, R. and Polasky, S., 2002. Agricultural sustainability and intensive production practices. Nature, 418(6898), pp.671-677.

Walker, M.J., Burns, M. and Burns, D.T., 2013. Horse meat in beef products-species substitution 2013. Journal of the Association of Public Analysts, 41, pp.67-106.

Weersink, A., 2017. The growing heterogeneity in the farm sector and its implications. Canadian Journal of Agricultural Economics. forthcoming.

Weersink, A., Livernois, J., Shogren, J.F. and Shortle, J.S., 1998. Economic instruments and environmental policy in agriculture. Canadian Public Policy/Analyse de Politiques, 24(3), pp.309-327.

Weersink, A., and Pannell, D., 2017. Payments versus direct controls for environmental externalities in agriculture, Oxford Research Encyclopedia of Environmental Science, October, 
http://environmentalscience.oxfordre.com/view/10.1093/acrefore/9780199389414.001. $\underline{0001 / a c r e f o r e-9780199389414-e-520 .}$

Weis, T., 2013. The ecological hoofprint: The global burden of industrial livestock. Zed Books Ltd.

Wolfert, S., Ge, L., Verdouw, C. and Bogaardt, M.J., 2017. Big Data in Smart Farming-A review. Agricultural Systems, 153, pp.69-80.

Wong, E.H.K. and Hanner, R.H., 2008. DNA barcoding detects market substitution in North American seafood. Food Research International, 41(8), pp.828-837.

Woodard, J.D., 2016a. Data science and management for large scale empirical applications in agricultural and applied economics research. Applied Economic Perspectives and Policy, 38(3), pp.373-388.

Woodard, J.D., 2016. Big data and Ag-Analytics: An open source, open data platform for agricultural \& environmental finance, insurance, and risk. Agricultural Finance Review, 76(1), pp.15-26. 